\title{
High Water Diffusivity in Low Hydration Plasma-Polymerised Proton Exchange Membranes
}

\author{
Vanessa K. Peterson ${ }^{1, a}$, Cormac Corr ${ }^{2, b}$, Gordon J. Kearley ${ }^{1}$, Roderick \\ Boswell ${ }^{2}$, Zunbeltz Izaola ${ }^{3}$ \\ ${ }^{1}$ The Bragg Institute, Australian Nuclear Science and Technology Organisation, Menai 2234, \\ Australia \\ ${ }^{2}$ Space Plasma, Power and Propulsion (SP3) Laboratory, Research School of Physics and \\ Engineering, The Australian National University, ACT, Australia \\ ${ }^{3}$ Berlin Neutron Scattering Center, Helmholtz Zentrum Berlin für Materialien und Energie, D-14109 \\ Berlin, Germany \\ avanessa.peterson@ansto.gov.au, ${ }^{\mathrm{a}}$ cormac.corr@anu.edu.au
}

Keywords: Polymer membranes, fuel cell membranes, neutron scattering, plasma polymerisation, diffusion, neutron scattering

\begin{abstract}
This paper compares proton diffusion through plasma-polymerised proton-exchange membranes (PEMs) produced using traditional wet-chemical methods (Nafion ${ }^{\circledR}$ ) and those produced using plasma-polymerisation. Using quasielastic neutron scattering and a simple model of proton motion we find the measured diffusion-rate of protons in the plasma-polymerised material and Nafion ${ }^{\circledR}$ is the same (within 1 standard error) even though the plasma-polymerised membrane has 80 $\%$ less water than the Nafion ${ }^{\circledR}$. We attribute this result to the highly cross-linked structure of the plasma-polymerised membrane.
\end{abstract}

\section{Introduction}

Proton exchange membrane (PEM) fuel cells are perhaps the best known fuel cell technology because of their potential to replace internal combustion engines for transportation applications [1]. The membrane functions using covalently linked acidic functionalities, as part of a membrane electrode assembly (MEA, the fuel cell), to conduct protons through to the cathode and force electrons through an external load that becomes an electricity source. The amount of electricity produced is directly proportional to the transport of protons through the membrane. The level of proton conduction in these membranes depends strongly on their hydration state. Studies of the water dynamics within these membranes are essential to understand the mechanism of proton conductivity and in advancing the development of new PEM materials.

Commercially available PEMs are produced using a wet-chemical method. This method does not provide easy alteration to the microstructural and chemical composition of the polymer, factors which affect the PEM performance. One way of producing PEMs is to use plasma polymerization, which enables the direct and rapid control of the PEM micro-structural characteristics and thickness (affording miniaturization) by changing the plasma parameters. The plasma process results in strong adhesion on electrodes and conformal coatings in the MEA and the cross-linked structure gives plasma polymers good chemical and thermal stability. Little work has been reported on transport properties of plasma polymers and substantial research and development is required to make plasma polymer membranes commercially competitive with other available materials produced by wet chemical processes. Despite the advantages of this method, there have been relatively few studies investigating the preparation of proton exchange membranes by plasma polymerisation [2-15].

Perhaps the most direct method of observing the interaction of protons in a PEM is through quasielastic neutron scattering (QENS), able to follow diffusive motions of water at timescales matching diffusion of protons in PEMs. In a QENS experiment, the neutrons exchange some energy 
with the moving nuclei that comprise the sample. Analysis of the energy exchange and the scattering wave-vector of the neutrons yield information concerning the motions of the nuclei, including their timescale and geometry. As scattering from hydrogen nuclei dominate the data, the information on the motions of the hydrogen nuclei are obtained, even in the presence of a complex polymer matrix. In the present work we apply QENS to study the motion of the hydrogen nuclei of the water added to the plasma-polymerised membranes, and compare this with the commercially available membrane, Nafion ${ }^{\circledR}$, developed via wet-chemical methods.

\section{Experimental Procedures}

Preparation and Characterization of PEMs. Plasma polymerized PEMs were produced using a pulsed-plasma enhanced chemical vapour-deposition (P-PECVD) system at the Space Plasma, Power and Propulsion $\left(\mathrm{SP}^{3}\right)$ group at The Australian National University. Trifluoromethanesulfonic acid and styrene precursors from Sigma-Aldrich were introduced to the system using mass-flow controllers. Gas lines were heated to avoid polymerisation and/or condensation of monomers on their walls. The total pressure in the reactor was 0.5 Torr and membranes were deposited onto Si substrates for structural characterisation and onto Al substrates for neutron studies. Nafion ${ }^{\circledR} 115$ membranes were purchased from Aldrich and treated by immersing in $\mathrm{H}_{2} \mathrm{O}_{2}$ at $60{ }^{\circ} \mathrm{C}$ for 1 hour, washed in de-ionized water, and then immersed in $\mathrm{H}_{2} \mathrm{SO}_{4}$ at $60{ }^{\circ} \mathrm{C}$ for 1 hour, before finally being washed in de-ionized water and dried in an oven at $100{ }^{\circ} \mathrm{C}$. FTIR spectra for both plasma and commercial membranes were collected at room temperature using a Nicolet FTIR spectrophotometer and a silicon wafer sample as background, in the range $4000-400 \mathrm{~cm}^{-1}$. The ion exchange capacity (IEC) of the polymer membranes were determined via titration. A dry weight of the polymer membrane was soaked in 30 $\mathrm{ml}$ of saturated $\mathrm{NaCl}$ solution at room temperature for 2 days and the polymer containing solution was titrated with a $0.005 \mathrm{M} \mathrm{NaOH}$ solution using phenolphthalein indicator. The IEC was calculated from the volume of consumed titrant times its molar concentration, divided by the weight of the dry membrane.

QENS Data Collection. QENS data were collected using the NEAT (V3) instrument at the Berlin Neutron Scattering Center. Incident neutrons at $\lambda=5.1 \AA$ were used in an instrument configuration that gave $\approx 140 \mu \mathrm{eV}$ energy resolution at the elastic line. Data for protons arising only from the water added to the membranes was determined by obtaining difference spectra between samples hydrated with $\mathrm{H}_{2} \mathrm{O}$ and $\mathrm{D}_{2} \mathrm{O}$ (where hydrogen nuclei scatter neutrons more strongly than deuterium nuclei). In the difference spectra the contribution from the membrane is subtracted and the remaining signal is from protons in the water. The scattering consists of elastically scattered neutrons (from protons confined or not moving on the timescale measurable by QENS) and quasielastically scattered neutrons (from diffusing protons moving through the membrane). The experimentally measured spectra were analysed using the scaled intensity of the elastic signal (using the instrument resolution function) plus the remaining quasielastic signal (using a Lorentzian function convoluted with the instrument resolution function), and a flat background, with the QENS_fit program in the LAMP environment [16].

\section{Results and Discussion}

Characterization of PEMs. The Fourier transform infrared (FTIR) spectra of the membranes at 25 ${ }^{\circ} \mathrm{C}$ are shown in Fig. 1 (left). Similarities between the spectra occur in the pronounced absorption $c a \sim$ 3800 to $3000 \mathrm{~cm}^{-1}$ and $c a \sim 1650 \mathrm{~cm}^{-1}$. These are assigned to $\mathrm{OH}$ stretching and $\mathrm{H}_{2} \mathrm{O}$ bending, respectively. These bands are less pronounced in the plasma-polymer indicating that Nafion ${ }^{\circledR}$ is a more hydrated material. Nafion ${ }^{\circledR}$ displays a broad band between 1030 and $1420 \mathrm{~cm}^{-1}$, containing overlapping contributions from the antisymmetric $\mathrm{CF}_{2}$ stretching and $\mathrm{SO}_{3}{ }^{-}$groups. For the plasma-polymerised membrane, bands in this region are observed due to the fragmentation of the trifluoromethane sulfonic acid. Due to the overlapping presence of other chemical groups coming from the fragmentation of styrene, the differentiation of bands related to $\mathrm{CF}_{\mathrm{x}}, \mathrm{SO}_{3} \mathrm{H}$ and $\mathrm{SO}_{3}{ }^{-}$groups 
is difficult. The most significant difference between the two spectra results from the chemical bonds arising from the fragmentation of styrene creating the plasma-polymer matrix, which are not observed in the Nafion ${ }^{\circledR}$ spectrum. Features assigned to aromatic C-H stretching vibrations are observed at 3060 and $3080 \mathrm{~cm}^{-1}$ and to $\mathrm{C}=\mathrm{C}$ stretching aromatic vibrations at 1600 and $1490 \mathrm{~cm}^{-1}$. This shows preservation of the monomeric phenyl rings during plasma polymerisation. Features related to aliphatic chains are located at 2960, 2927 and $2844 \mathrm{~cm}^{-1}$. The intensity of these features indicates significant cross-linking in the plasma polymers. In the polymerisation of styrene for fuel-cell membranes, the cross-linking has a strong impact on the membrane performance, increasing the mechanical strength and the chemical stability, and decreasing the swelling and toughness. The increase in the degree of cross-linking of the membranes results in a more compact structure.
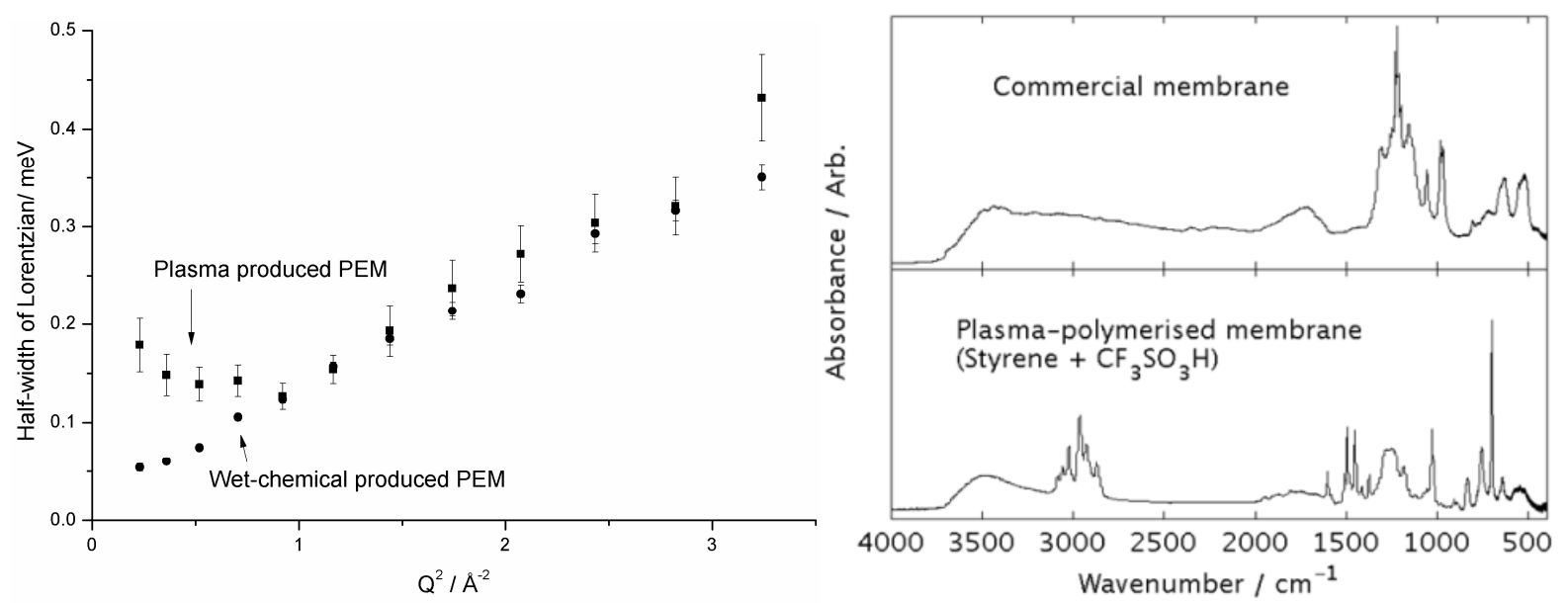

Fig. 1 Left: FTIR spectra of plasma-prepared and Nafion ${ }^{\circledR}$ PEMs. Right: Trend of quasielastic broadening in QENS data for plasma (squares) and Nafion ${ }^{\circledR}$ (circles) membranes.

The ion-exchange capacity (IEC) for the plasma membrane was measured to be 0.7 mequiv. $\mathrm{g}^{-1}$, similar to that of other membranes produced using plasma polymerisation [17] and less than that of Nafion $^{\circledR}\left(\sim 0.91\right.$ mequiv. $\left.^{-1}\right)$. The highly cross-linked structure of the plasma membrane, indicated by the FTIR spectra, suppresses the water uptake of ion exchangers and hinders swelling, arising from the decreased molecular mobility associated with the tight network structure. This is consistent with water uptake measurements in the plasma-produced membranes of $\sim 3.0 \%$, significantly lower that that of $\sim 15 \%$ for the Nafion ${ }^{\circledR}$.

QENS Measurement of Proton Motions. Fig 1 (right) shows the quasielastic broadening for both membranes as a function of $\mathrm{Q}^{2}$. The constant value of the half-width at half-maximum (HWHM) of the quasielastic contribution at low $\mathrm{Q}$ arises from protons that are confined. At all hydration levels for Nafion ${ }^{\circledR}$ a similar trend of constant value at low $Q$ followed by increase in value at high $Q$ has been noted [21] and we find this region to be $\mathrm{Q}<0.48 \AA^{-1}$ for $\mathrm{Nafion} \AA$ and $\mathrm{Q}<0.96 \AA^{-1}$ for the plasma membrane. We note a larger value of HWHM for the Lorentzian component of the plasma membrane compared with Nafion ${ }^{\circledR}$ in the low Q region of this data, this will be investigated further in future work.

A variety of models have been used to describe the motions of water in Nafion ${ }^{\circledR}$ membranes measured with QENS [18-23]. In order to compare the two types of sample, rather than to make a detailed analysis of the diffusion process, the long-range self-diffusion coefficient constant, $\mathrm{D}$, for the protons in the water was considered and approximated to Fickian diffusion, in the region where quasielastic broadening is observed $\left(Q=0.96-1.68 \AA^{-1}\right)$. In this approximation the Lorentzian widths are proportional to $\mathrm{DQ}^{2}$ and we determine $\mathrm{D}$ through a linear weighted fitting of a straight line to data. The proton diffusivity was found to be $1.70(9) \times 10^{-5} \mathrm{~cm}^{2} \mathrm{~s}^{-1}$ for the plasma membrane, within one standard error of that for the Nafion ${ }^{\circledR}, 1.63(5) \times 10^{-5} \mathrm{~cm}^{2} \mathrm{~s}^{-1}$. These values are within the range of values reported for Nafion ${ }^{\circledR}$ using the same QENS model [23-24] and are significantly lower than that for freely diffusing water [23]. 


\section{Summary}

Quasielastic neutron scattering was used to compare the diffusion of water in plasma polymerised and Nafion ${ }^{\circledR}$ PEMs. This work revealed that the average rate of self-diffusion of protons through the plasma polymerised and Nafion ${ }^{\circledR}$ membranes is the same, a noteworthy result as diffusivity increases with water content, which was $15 \%$ in the Nafion ${ }^{\circledR}$ and $3 \%$ in the plasma membrane.

\section{References}

[1] M.A. Hickner, B.S. Pivovar, Fuel Cells 5 (2005) 213

[2] N. Inagaki, S. Tasaka, Z. Chengfei, Polym. Bull. 26 (1991) 187.

[3] N. Inagaki, S. Tasaka, Y. Horikawa, J. Polym. Sci. Pol. Chem. 27 (1989) 3495.

[4] N. Inagaki, S. Tasaka, T. Kurita, Polym. Bull. 22 (1989) 15.

[5] Z. Ogumi, Y. Uchimoto, Z. Takehara, J. Electrochem. Soc. 137 (1990) 3319.

[6] Z. Ogumi, Y. Uchimoto, K. Yasuda, Z.I. Takehara, Chem. Lett. (1990) 953.

[7] C.J. Brumlik, A. Parthasarathy, W.J. Chen, C.R. Martin, J. Electrochem. Soc. 141 (1994), 2273.

[8] K. Yasuda, Y. Uchimoto, Z. Ogumi, Z. Takehara, J. Electrochem. Soc. 141 (1994), 2350.

[9] L. Mex, J. Müller, Membrane Technology 1999 (1999), 5.

[10] H. Mahdjoub, S. Roualdes, P. Sistat, N. Pradeilles, J. Durand, G. Pourcelly, Fuel Cells 5 (2005), 277.

[11] A. Ennajdaoui, S. Roualdes, P. Brault, J. Durand, J. Power Sources, 195, (2010), 232.

[12] S. Roualdes, M. Schieda, L. Durivault, I. Guesmi, E. Gerardin, J. Durand, Chem. Vapor Depos. 13 (2007) 361.

[13] S. Roualdes, I. Topala, H. Mahdjoub, V. Rouessac, P. Sistat, J. Durand, J. Power Sources 158 (2006), 1270.

[14] Z. Jiang, Y. Meng, Y. Shi, Jpn. J. Appl. Phys. 47 (2008), 6891.

[15] Z.Q. Jiang, Y.D. Meng, Z.J. Jiang, Y.C. Shi, Surf. Rev. Lett. 14 (2007), 1165.

[16] http://www.ill.fr/data_treat/lamp/front.html.

[17] K. Yasuda, Y. Uchimoto, Z. Ogumi, Z. Takehara, J. Electrochem. Soc. 141 (1994) 2350.

[18] O.E. Haas, J.M. Simon, S. Kjelstrup, A.L. Ramstad, P. Fouquet, J. Phys. Chem. C 112 (2008), 3121.

[19] K.A. Page, J.K. Park, R.B. Moore, V.G. Sakai, Macromolecules 42 (2009) 2729.

[20] J.C. Perrin, S. Lyonnard, F. Volino, J. Phys. Chem. C 111 (2007), 3393.

[21] A.A. Pivovar, B.S. Pivovar, J. Phys. Chem. B 109 (2005), 785.

[22] A.L. Rollet, J.P. Simonin, P. Turq, G. Gebel, R. Kahn, A. Vandais, J.P. Noel, C. Malveau, D. Canet, J. Phys. Chem. B 105 (2001) 4503.

[23] F. Volino, M. Pineri, A.J. Dianoux, J. Polym. Sci. Pol. Chem. 20 (1982) 481.

[24] A. J. Dianoux, M. Pineri, F. Volino, Mol. Phys. 46 (1982) 129 